\title{
Innovative Forms of Employment Under the Conditions of Labor Market Transformation
}

\author{
Submitted 11/02/20, $1^{\text {st }}$ revision 19/04/20, $2^{\text {nd }}$ revision 25/05/20, accepted 20/07/20
Galyna Lopushnyak ${ }^{1}$, Victoria Overchuk ${ }^{2}$, Liliya Ukraynets ${ }^{3}$, Svetlana Rudakova $^{4}$, Dmytro Kabachenko ${ }^{5}$

\begin{abstract}
:
Purpose: In modern conditions new forms of employment are being introduced. The purpose of scientific investigation is to reveal and analyze the theoretical, methodological and practical aspects of employment's innovative forms in the transformation of the labor market. Design/Methodology/Approach: The theoretical, methodological and practical aspects of innovative forms of employment in the labor market transformation are presented on the basis of theoretical analysis and synthesis, induction and deduction, and empirical research methods, such as measurement, observation and comparison.

Findings: The investigation of the materials submitted by Eurofound has made it possible to reveal 9 key innovative forms of employment, which are widely implemented by the member states of the European Union and not only by them, namely: employee sharing, job sharing, interim management, casual work, ICT-based mobile work, voucher based work, portfolio work, crowd employment, collaborative employment.

Originality/Value: The dynamics of employment in the member states of the European Union during 2014-2019 have been estimated. The interdependence between the rate of job vacancies by NACE activities (Job vacancy rate by NACE Rev.) and the share of temporary employees in such countries as Ireland, Luxembourg, Portugal and Croatia has been presented.
\end{abstract}

Keywords: Innovative forms of employment, non-standard forms of employment, labor market, job vacancies, temporary employment.

JEL Codes: J19, J21, J40.

Article Type: Research paper.

\footnotetext{
${ }^{l}$ Professor, Kyiv National Economic University named after Vadym Hetman.

E-mail: halstep@ukr.net;

${ }^{2}$ Associate professor, Vasyl Stus Donetsk National University.

E-mail: vik.over030506@gmail.com;

${ }^{3}$ Associate professor, Ivan Franko National University of Lviv.

E-mail: lilia.ukrainets@gmail.com;

${ }^{4}$ Associate professor, Kyiv National Economic University named after Vadym Hetman.

E-mail: svetlana.rudakova@gmail.com;

${ }^{5}$ Associate professor, Dnipro University of Technology.E-mail: Kabachenko.D.V@nmu.one;
} 


\section{Introduction}

In modern conditions of labor market transformation, new forms of employment are precipitately being introduced into business development. In addition, with the development of information technologies that significantly affect the nature of doing business, it is becoming increasingly common among employers to use non-standard forms of employment as the result of their application in practice giving positive changes to the system of management, development and business. Consequently, all of the above mentioned determines the relevance of the subject matter of this academic paper. Therefore, based on the relevance of the subject matter the purpose of this scientific research is to reveal and analyze the theoretical, methodological and practical aspects of innovative forms of employment under the conditions of labor market transformation.

\section{Literature Review}

In the context of disclosure and analysis of theoretical and methodological principles of innovative forms of employment under the conditions of labor market transformation, it is worth considering the scientific investigations of leading scientists and scholars, specializing in the study of the above mentioned problems. It should be noted that Sanduhey (2015), in the course of studying the issue of innovative types' formation of employment in the economy, states that currently the following forms of employment are used in business, namely:

1. forced underemployment, causing partial unemployment;

2. part-time employment;

3. non-standard forms of employment, including temporary employment, employment on a part-time basis, remote employment, employment in the field of outsourcing, outstaffing or staff leasing;

4. non-standard job vacancies, including work from home, work on call;

5. flexible (inflexible) working schedule.

Barbieri et al. (2016) have surveyed 265 Italian enterprises (firms) engaged in innovation activities. According to the results of the survey, scientists have determined the impact of innovative activities of enterprises (firms) on employment, where the level of impact was based on such indicators as the cost of research and development, experimental-design works and the level of technological change. Consequently, it has been established that "the positive employment impacts of innovation activities and $R \& D$ expenditures are totally due to firms operating in high-tech industries and large companies, while no job-creation due to technical change is detectable in traditional sectors and SMEs" (Barbieri et al., 2016). In addition, Vivarelli (2012), in his research, studies the features of the quantitative and qualitative impact of innovation on employees' employment. 
At the same time, Galayda et al. (2018), studying non-standard forms of employment, note that the basic non-standard forms of employment should include full employment, part-time employment of temporary workers, employment on the basis of secondary employment, informal employment, employment on call, employment on loan, employment at home, etc.

Herewith, Il'ich (2015), considering issues of the innovative employment's model, states that modern innovative forms of employment should be based on the provisions of humanization, intellectualization and informatization of employment, as well as improving the quality of human capital, which, in turn, will contribute to the emergence of new types of employment.

In the course of the disclosure of the theoretical and methodological principles of the academic paper's subject matter, attention should also be paid to the study carried out by a team of such scientists, as Akimov et al. (2020a; 2020b). Therefore, scholars in the context of improving the level of development and efficiency of doing business propose to improve the qualities of managers who carry out management activities. Such actions will improve the business in the future, as well as increase the employment rate of managers (Akimov et al., 2020b).

\section{Data and Methods of Research}

The theoretical, methodological and practical aspects of innovative forms of employment in the labor market transformation are presented in the academic paper on the basis of using: 1) methods of theoretical analysis and synthesis, induction and deduction in order to study key theoretical and methodological aspects of innovative forms of employment; 2) empirical research methods, such as measurement, observation and comparison to study the features of the formation of employment's innovative forms in practice in the context of research and analysis of key trends.

Eurofound materials and data are the methodological basis for revealing the practical aspects of the formation of innovative forms of employment in the conditions of labor market transformation. At the same time, the presentation of practical research results is reflected through such indicators, as:

1. dynamics of employment in the member states of European Union (Eurostat, 2020a);

2. level of job vacancies by NACE activities (Eurostat, 2020b);

3. the share of temporary workers (Eurostat, 2020c).

\section{Results of the Research}

In the course of revealing the practical aspects of the formation of employment's innovative forms in the context of the transformation of the labor market, it is necessary to analyze the current trends in these forms, which are currently traced. 
Thus, on the basis of the development of one of the agencies of the European Union, namely the European Fund, which main competence centers around improving living and working conditions, it should be noted that in the context of determining new forms of employment, the following aspects should be taken into account (according to studies conducted by Mandl et al. (2015), which are reflected in Figure 1.

Figure 1. Key aspects of new forms of employment's formation

\begin{tabular}{|c|c|}
\hline $\begin{array}{l}\text { Labor relations (between one } \\
\text { and many; between many and } \\
\text { one; between many and many) }\end{array}$ & $\begin{array}{l}\text { Non-traditional place of employment } \\
\text { (namely employment in one's own } \\
\text { office or employment in a mobile office) }\end{array}$ \\
\hline $\begin{array}{l}\text { Features of employment } \\
\text { (intermittent; with a fixed } \\
\text { term) }\end{array}$ & $\begin{array}{l}\text { Availability of workplace support with } \\
\text { information and communication } \\
\text { technologies (including the availability } \\
\text { of a mobile phone, etc.) }\end{array}$ \\
\hline \multirow{2}{*}{$\begin{array}{l}\text { Features of data transmission } \\
\text { networks (between self- } \\
\text { employed; between } \\
\text { representatives of medium and } \\
\text { small businesses) }\end{array}$} & $\begin{array}{l}\text { Employment regardless of the features } \\
\text { of the collective agreement or legal } \\
\text { framework }\end{array}$ \\
\hline & $\begin{array}{l}\text { Employment regardless of field of } \\
\text { activity or specialization }\end{array}$ \\
\hline
\end{tabular}

Source: Based on Mandl et al. (2015) and Eurofound (2018).

Mandl et al. (2015) (according to Eurofound materials) identify 9 new forms of employment, including: 1) Employee sharing; 2) Job sharing; 3) Interim management; 4) Casual work; 5) ICT-based mobile work; 6) Voucher based work; 7) Portfolio work; 8) Crowd employment; 9) Collaborative employment.

It should be noted that according to studies conducted by Mandl et al. (2015), the implementation of Employee sharing is observed among the member states of the European Union, namely in Austria, Belgium, Bulgaria, Greece, Luxembourg, Germany, Hungary, Finland, France and the Czech Republic. Along with that, employment based on job sharing is implemented in the UK, Ireland, Italy, Poland, Slovakia, Slovenia, Hungary and the Czech Republic. At the same time, employment based on the form of Interim management is observed in such countries, as the United Kingdom, Greece, Latvia, Hungary, France and the Czech Republic. Casual work implementation is presented in Belgium, the United Kingdom, Ireland, Italy, the Netherlands, Romania, Slovakia, Slovenia, Hungary, France, Croatia and Sweden. In turn, employment based on ICT-based mobile work is most common among EU member states; it is implemented in Belgium, Greece, Denmark, Spain, Cyprus, Latvia, Lithuania, the Netherlands, Germany, Portugal, Slovenia, Hungary, Finland, France and Sweden. In addition, Voucher based work is concentrated only in Austria, Belgium, Greece, Italy, Lithuania and France. Along with that, Portfolio 
work-based employment is concentrated in the United Kingdom, Greece, Denmark, Italy, Cyprus, Latvia, Lithuania, the Netherlands, Portugal and Hungary. Meanwhile, Crowd employment has been introduced in Belgium, the United Kingdom, Greece, Denmark, Spain, Italy, Latvia, Lithuania, Germany, Portugal and the Czech Republic. In turn, Collaborative employment has been introduced in Austria, Belgium, Greece, Spain, Italy, Cyprus, Lithuania, the Netherlands, Germany, Hungary, France and Sweden (Mandl et al., 2015).

In the course of the investigation conducted, the attention should be focused on studying the basic trends in employment dynamics (on the example of EU member states). Consequently, based on the processing of data provided by Eurostat, it should be noted that the lowest employment rate in 2014-2019 was observed in Italy, but in 2019, in contrast to 2014, the share of employment in this country increased by $2,9 \%$ (Table 1). In addition to Italy, low employment rate during the period under review was revealed in Germany, Portugal, Romania, Slovakia, Hungary, Croatia and the Czech Republic. For instance, in Germany in 2019 compared to the beginning of the analyzed period the share of employment increased by $2,9 \%$, and in Slovakia - by as much as 5,4\%. There was a slight increase in the share of employment in all the above mentioned countries, however, it was lowest in Hungary (the increase in the share of employment was only $0,6 \%$ ).

Table 1. Dynamics of employment in the member countries of European Union

\begin{tabular}{|l|c|c|c|c|c|c|}
\hline \multicolumn{1}{|c|}{ Countries } & $\mathbf{2 0 1 4}$ & $\mathbf{2 0 1 5}$ & $\mathbf{2 0 1 6}$ & $\mathbf{2 0 1 7}$ & $\mathbf{2 0 1 8}$ & $\mathbf{2 0 1 9}$ \\
\hline Austria & 31,1 & 31,8 & 32,9 & 33,7 & 33,3 & 34,3 \\
\hline Belgium & 42,5 & 42,8 & 43,3 & 44,2 & 43,1 & 44,2 \\
\hline Bulgaria & 31,8 & 32,5 & 32,9 & 31,4 & 32,2 & 31,1 \\
\hline The United Kingdom & 41,5 & 42,8 & 42,3 & 42,4 & 42,7 & 44,5 \\
\hline Greece & 39,2 & 39,1 & 40,7 & 41,3 & 42,1 & 41,6 \\
\hline Denmark & 35,3 & 36,0 & 36,2 & 37,7 & 38,0 & 38,8 \\
\hline Estonia & 38,2 & 38,7 & 39,4 & 39,6 & 40,4 & 41,1 \\
\hline Ireland & 50,0 & 51,1 & 50,4 & 51,5 & 51,2 & 50,9 \\
\hline Spain & 44,4 & 44,3 & 44,2 & 44,3 & 45,0 & 44,7 \\
\hline Italy & 19,4 & 20,1 & 20,3 & 21,5 & 22,1 & 22,3 \\
\hline Cyprus & 46,2 & 46,2 & 47,3 & 46,4 & 46,9 & 48,1 \\
\hline Latvia & 34,1 & 35,8 & 37,9 & 36,9 & 38,0 & 40,0 \\
\hline Lithuania & 44,2 & 45,5 & 45,8 & 45,8 & 46,1 & 48,0 \\
\hline Luxembourg & 48,0 & 42,7 & 42,6 & 42,5 & 46,3 & 49,4 \\
\hline Malta & 27,7 & 28,4 & 28,4 & 29,5 & 32,1 & 32,6 \\
\hline The Netherlands & 34,6 & 35,7 & 36,1 & 36,6 & 37,7 & 39,1 \\
\hline Germany & 25,5 & 26,3 & 26,9 & 27,2 & 27,6 & 28,4 \\
\hline Poland & 34,9 & 35,7 & 35,8 & 36,5 & 37,2 & 38,0 \\
\hline Portugal & 26,3 & 27,2 & 27,8 & 27,8 & 28,6 & 29,3 \\
\hline Romania & 25,4 & 26,9 & 26,6 & 26,3 & 26,0 & 26,4 \\
\hline Slovakia & 22,2 & 22,9 & 23,4 & 24,7 & 26,2 & 27,6 \\
\hline Slovenia & 34,5 & 35,7 & 35,7 & 36,5 & 36,3 & 36,9 \\
\hline Hungary & 26,1 & 26,3 & 25,4 & 25,5 & 26,1 & 26,7 \\
\hline
\end{tabular}




\begin{tabular}{|l|l|l|l|l|l|l|}
\hline Finland & 43,4 & 44,5 & 45,4 & 44,5 & 46,0 & 46,7 \\
\hline France & 37,5 & 38,3 & 39,0 & 39,4 & 41,0 & 42,1 \\
\hline Croatia & 28,1 & 29,0 & 28,8 & 29,2 & 30,2 & 29,8 \\
\hline The Czech Republic & 23,1 & 22,8 & 23,3 & 24,3 & 23,8 & 24,0 \\
\hline Sweden & 39,2 & 40,2 & 41,5 & 42,1 & 43,4 & 44,5 \\
\hline
\end{tabular}
Explanation of Symbols:
low employment rate.

Source: Composed based on Eurostat (2020a).

In contrast to countries with low levels of employment, Belgium, the United Kingdom, Ireland, Spain, Cyprus, Lithuania, Luxembourg, Finland and Sweden have shown high levels of employment among EU member states. Thus, among the selected countries, Ireland has the highest employment rate, which is more than $50 \%$. In 2019, compared with 2014, the highest growth in the share of employees among countries with a high level of employment was demonstrated by Sweden, Lithuania and France, where the share of employees increased by 5,3\%, 3,8\% and 3,3\%, respectively. Among the member states of European Union, only in Bulgaria in 2019 , compared with the beginning of the analyzed period, there was a decline in employment, where the share of employment decreased by $0,7 \%$.

Regarding the specification of European Union member states, Figure 2 shows the interdependence between the level of job vacancies by NACE activities (Eurostat, $2020 \mathrm{~b}$ ) and the share of temporary employees in such countries, as Ireland and Luxembourg (these countries obtain the highest employment rate) and Portugal and Croatia (these countries obtain the lowest employment rate). The highest job vacancies' rates by NACE activities among the countries studied are revealed in Portugal and Croatia, although these countries are referred to countries with low employment rate.

On the other hand, the smallest number of temporary workers is involved in the business of such countries, as Ireland and Croatia, and this is due to the fact that there is a high level of employment of permanent workers in these countries. A decrease in the level of free job vacancies by NACE activities and at the same time an increase in the share of temporary workers is clearly observed in such country as Ireland, because temporary workers are actively occupying the free job vacancies represented in the country every year. In contrast to Ireland, in the other three countries studied (Luxembourg, Portugal and Croatia) there is an unstable dynamics of the interdependence of job vacancies' level by NACE activities and the share of temporary workers. While studying the practical aspects of the formation of employment's innovative forms, the example of the Japanese automobile corporation "Toyota" should be mentioned, where back in 1951 "Creative Ideas Suggestive System" was developed and implemented; according to it currently (as of 2015) there are 40 million ideas from employees of this corporation, which are at different levels of the organization regarding the improvement of the corporation. 
Figure 2. Analysis of employment in some member states of European Union

Ireland
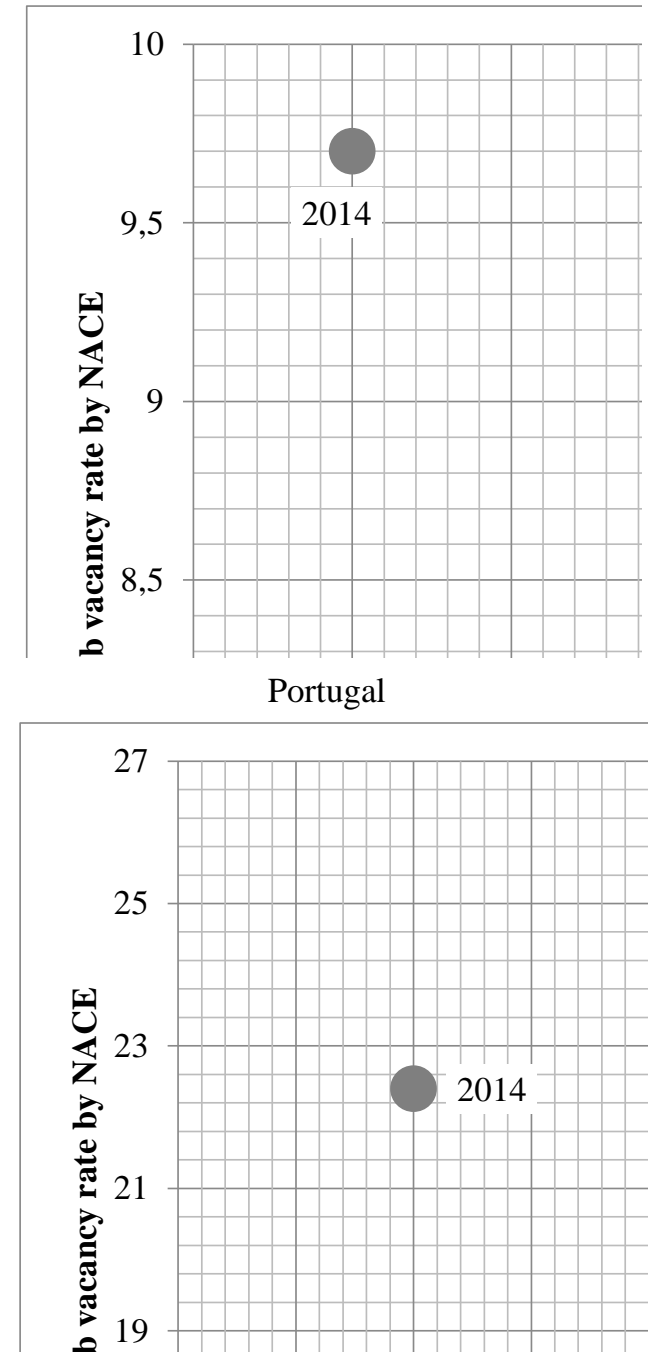

Luxembourg
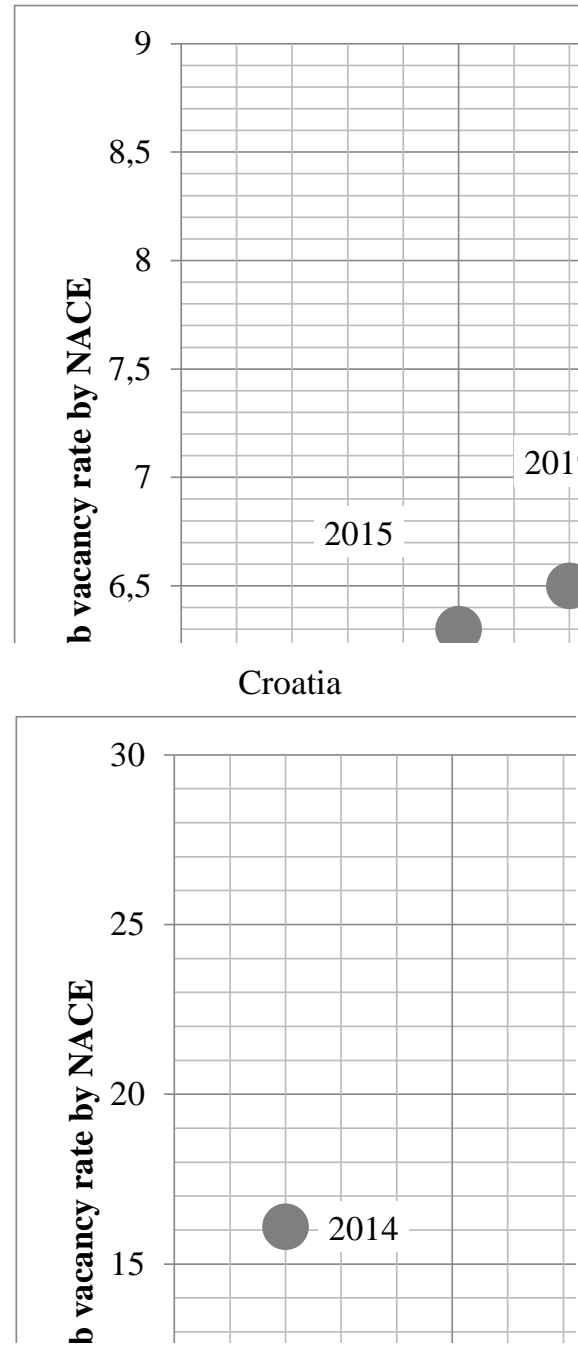

Source: Composed based on Eurostat (2020b), Eurostat (2020c).

As Morgan (2015) points out, not every idea, submitted by employees, was implemented by corporation "Toyota", however, there were cases when the level of implementation of ideas, submitted by employees, was more than $98 \%$. Therefore, it should be noted that the corporation "Toyota" obtains a successful innovation program, in which employees, receiving incentives and motivation to work, effectively present to the management of the corporation their own ideas about the future operation and development of this corporation and for each time their ideas are stimulated (Morgan, 2015). 
Another vivid example of the introduction of employment's innovative forms, according to research of Morgan (2015), is the American corporation "Whirlpool". Thus, more than 90,000 employees are employed in this corporation, which has its factories around the world. In the context of improving production efficiency, which is the basic goal of this corporation, "Whirlpool" management has developed and implemented an innovative program, according to which employees of the corporation can put forward their own ideas for improving production through online platform tools, specially developed by the corporation. Corporation "Whirlpool" is guided by a holistic structured process of innovation, which is usually called the "laboratories of ideas" within the corporation in order to implement the developed innovation program (Morgan, 2015).

According to the results of studies presented by BusinessVictoria (n./d.), it should be noted that it is innovations that play an important role in the system of increasing employment, foremuch as the introduction of a culture of innovation in any sphere of business currently is the key to encouraging employees to participate in the functioning and future development of the business. Therefore, the algorithm for introducing innovative forms of employment in business consists of such blocks (BusinessVictoria, n./d.):

1. to encourage employees to maintain an order of innovation culture in the business system (in particular, employees should be honest and openminded, always share their own ideas about the development and prosperity of business, as well as take the initiative in business development);

2. to attract in the business employees, who share different visions, but are aimed at ensuring the success of the activity (that is, employees who may have their own personal vision of the situation, but the eventual outcome of this vision should be focused on the prospects of business development);

3. to encourage employees to present their own ideas for business development, involving them in meetings, as well as personally communicating with them);

4. to introduce a clear review of ideas, suggestions and recommendations proposed by employees;

5. to ensure the rapid implementation of ideas, proposals and recommendations submitted by employees, if they are recognized as promising and conducive to business development;

6. to encourage employees to present ideas, suggestions and recommendations with various motivational and stimulating means, even in cases when the proposed idea, proposal or recommendations have not been implemented in business;

7. to create favorable conditions and appropriate opportunities for employees in order to produce ideas, proposals and recommendations for future development and doing business;

8. to involve employees in educational trainings in order to form new approaches to perspective development and doing business; 
9. to invest a number of resources in the development of employment's innovative forms, foremuch as this will in the long run encourage employees to participate in the long-term development and conducting business.

\section{Discussion}

The problems of determining effective forms of employment, which, moreover, should be based on the development of modern scientific, technical, technological and innovative processes, are one of the key tasks of a modern business system. It should be noted that the issue of determining forms of employment, in particular nowadays, when significant transformational processes are taking place in the labor market, is extremely relevant; therefore, it requires constant research in the outlined direction.

Studying of the scholars' scientific heritage has proved that currently the following forms of employment are used in the modern business system, and they are mainly innovative in nature, namely: full-time employment, part-time employment, temporary employment, employment on a part-time basis, employment in the areas of outsourcing, outstaffing and leasing, remote employment, employment in the conditions of a flexible working schedule, employment in the conditions of an inflexible working schedule; employment on call, employment at home, etc.

At the same time, studies of the materials presented by Eurofound make it possible to identify 9 key innovative forms of employment that are widely implemented by member countries of European Union and not only by them, namely: Employee sharing, Job sharing, Interim management, Casual work, ICT-based mobile work, Voucher based work, Portfolio work, Crowd employment, Collaborative employment.

While estimating the dynamics of employment in EU member states, it has been found that such countries, as: Belgium, the United Kingdom, Ireland, Spain, Cyprus, Lithuania, Luxembourg, Finland and Sweden have a high level of employment during the study period of 2014-2019 among these countries. In the course of comparing the materials provided by Eurofound with employment data, it has been revealed that the above mentioned countries, having a high level of employment, are actively implementing certain innovative forms of employment identified by Eurofound. It has been determined that low employment rate during the analyzed period was observed in Italy, Germany, Portugal, Romania, Slovakia, Hungary, Croatia and the Czech Republic.

The study, based on Eurostat data, presents the interdependence between the vacancies' rate by NACE activities (Eurostat, 2020b) and the share of temporary employees in such countries, as Ireland and Luxembourg (these countries obtain the highest employment rate) and Portugal and Croatia (these countries obtain the lowest employment rate). 


\section{Conclusions}

Therefore, in the context of the disclosure and analysis of the theoretical, methodological and practical aspects of employment's innovative forms under the conditions of the labor market's transformation, a number of innovative forms of employment have been identified; currently they are used by the modern business system.

According to the results of the analysis and assessment of employment dynamics in the member states of European Union, countries with a high level of employment and countries with a low level of employment have been identified.

In the course of determining the interdependence between the indicators of the level of job vacancies by NACE activities and the share of temporary workers in such countries as Ireland, Luxembourg, Portugal and Croatia, it has been established that a decrease in the level of job vacancies by NACE activities and at the same time an increase in the share of temporary workers is clearly observed in such country as Ireland, foremuch as temporary workers actively occupy the vacancies represented in the country every year. In contrast to Ireland, Luxembourg, Portugal and Croatia have unstable dynamics of the interdependence of job vacancies' level by NACE activities and the share of temporary workers.

The conducted studies also made it possible to identify the algorithm for implementing innovative forms of employment in business, which consists of 9 blocks.

\section{References:}

Akimov, O., Karpa, M., Parkhomenko-Kutsevil, O., Kupriichuk, V., Omarov, A. 2020a. Entrepreneurship education of the formation of the e-commerce managers professional qualities. Journal of Entrepreneurship Education, 23(S1).

Akimov, O., Troschinsky, V., Karpa, M., Ventsel, V., Akimova, L. 2020b. International experience of public administration in the area of national security. Journal of Legal, Ethical and Regulatory Issues, 23(3), 34-45.

Barbieri, L., Piva, M., Vivarelli, M. 2016. The employment impact of different forms of innovation: Evidence from Italian community innovation survey. Vita E Pensiero, Milan.

BusinessVictoria. n./d. Improving employee innovation: Increase profitability and staff retention with an innovative culture. Available at: https://www.business.vic.gov.au/marketing-and-sales/growth-innovation-andmeasurement/improving-business-innovation-and-examples.

Eurofound. 2018. Overview of New Forms of Employment - 2018 Update. Publications Office of the European Union, Luxembourg.

Eurostat. 2020a. Employees by educational attainment level, sex, age and size of the local unit $(\%)$. Available at: https://appsso.eurostat.ec.europa.eu/nui/show.do?dataset=edat_lfs_9908\&lang=en. 
Eurostat. 2020b. Job vacancy rate by NACE Rev. 2 activity - annual data (from 2001 onwards). Available at:

https://appsso.eurostat.ec.europa.eu/nui/show.do?dataset=jvs_a_rate_r2\&lang=en.

Eurostat. 2020c. Temporary employees as percentage of the total number of employees, by sex, age and country of birth (\%). Available at: https://appsso.eurostat.ec.europa.eu/nui/show.do?dataset=lfsa_etpgacob\&lang=en.

Galayda, T.A., Tenytska, N.B., Chernogorska, N.V. 2018. Non-standard forms of employment of personnel of the subjects entrepreneurship and prospects for their development in Ukraine. Problems of Systemic Approach in the Economy, 65(3), 6673.

Il'ich, L.M. 2015. Innovative model of employment: the nature, characteristics and preconditions of formation in Ukraine. Rynok praci ta zajnjatistj naselennja, 2, 13-17.

Mandl, I., Curtarelli, M., Riso, S., Vargas Llave, O., Gerogiannis, E. 2015. New forms of employment. Available at:

https://www.eurofound.europa.eu/publications/report/2015/working-conditionslabour-market/new-forms-of-employment.

Morgan, J. 2015. The 5 Types of innovation for the future of work, pt. 1: Employee innovation. Forbes. Available at:

https://www.forbes.com/sites/jacobmorgan/2015/07/27/the-5-types-of-innovation-forthe-future-of-work-pt-1-employee-innovation/\#28e540bf7e20.

Sanduhey, V.V. 2015. Formation of innovative type of employment in national economy. M. P. Drahomanov NPU Scientific journal. Series 18, Economics and Law, 30, 22-28.

Vivarelli, M. 2012. Innovation, employment and skills in advanced and developing of economic literature. Journal of Economic, 48(1), 123-154.

https://doi.org/10.2753/JEI0021-3624480106. 